\title{
Correlation Analysis Among Genotype Resistance, Phenotype Resistance and Eradication Effect of Helicobacter pylori
}

\author{
Rongli Cui* \\ Zhiqiang Song* \\ Baojun Suo \\ Xueli Tian \\ Yan Xue \\ Lingmei Meng \\ Zhanyue Niu \\ Zhu Jin \\ Hejun Zhang \\ Liya Zhou $\mathbb{D}$
}

Department of Gastroenterology, Peking University Third Hospital, Beijing,

I00191, People's Republic of China

*These authors contributed equally to this work

\begin{abstract}
Background: It has not been fully confirmed whether the detection of Helicobacter pylori resistance gene mutation can replace antibiotic drug sensitivity test to guide the clinical individualized treatment. Therefore, we have studied this aspect and discussed the application value of antibiotic sensitivity gene test.
\end{abstract}

Materials and Methods: The biopsy specimen of gastric mucosa from the patients examined by endoscopy and positive for rapid urease test were collected continuously for histopathological analysis, H. pylori culture, antibiotic drug sensitivity test (E-test drug sensitivity test), and antibiotic sensitivity gene test (high-throughput nucleotide sequencing). The participants received triple plus bismuth solution eradication treatment (esomeprazole $20 \mathrm{mg}$, amoxicillin $1000 \mathrm{mg}$, clarithromycin $500 \mathrm{mg}$, and bismuth potassium citrate $220 \mathrm{mg}$, twice daily for 14 days) for follow-up, and the eradication effect was determined.

Results: The 551/602 subjects, who met the inclusion criteria, were subjected to culture for H. pylori and antibiotic drug sensitivity determination; among them 506 were cultured successfully. The results showed that the resistance rates of $H$. pylori were $38.9 \%$ for clarithromycin and $31.0 \%$ for levofloxacin. In $489 \mathrm{H}$. pylori strains, the mutations were detected in clarithromycin and levofloxacin resistance genes, indicating the genotype resistance. The resistance genes of clarithromycin and levofloxacin were consistent with phenotype resistance with respect to sensitivity $(81.2 \%$ and $69.7 \%$ for clarithromycin and levofloxacin, respectively) and specificity $(88.9 \%$ and $93.7 \%$ for clarithromycin and levofloxacin, respectively). The eradication rate of $\mathrm{H}$. pylori in the clarithromycin-resistant group was significantly lower than that in the sensitive group (ITT: $52.1 \%$ vs $85.0 \%, \mathrm{P}<0.001$ ). Conclusion: A correlation was established between the resistance genes of clarithromycin and levofloxacin and their phenotypic resistance and clinical efficacy. The detection of H. pylori resistance genes has a good clinical application prospect.

Keywords: Helicobacter pylori, drug resistance, clarithromycin, levofloxacin, mutation, high-throughput nucleotide sequencing

\section{Introduction}

Helicobacter pylori (H. pylori) is prevalent in more than half the world. ${ }^{1}$ H. pylori infection is an important pathogenic factor of chronic gastritis, peptic ulcer, gastric cancer and other common stomach diseases. Eradication of $H$. pylori infection can eliminate active inflammation in the stomach, accelerate the concrescence and healing of ulcer, delay the occurrence and development of gastric mucosa atrophy and intestinal metaplasia, and reduce the risk of gastric cancer. ${ }^{2-6}$ However, the
Correspondence: Liya Zhou

Department of Gastroenterology, Peking University Third Hospital, 49 Road

Garden, Haidian District, Beijing, I00191,

People's Republic of China

Tel +86-|39| 1827827

Fax +86-I0-8226502I

Email zhouliya123456@163.com 
resistance rate to clarithromycin, metronidazole, and levofloxacin in most countries and regions has increased significantly. $^{7}$ Especially, the clarithromycin-resistant H. pylori strains have been listed as the top priority among the antibiotic-resistant bacteria under research by the World Health Organization. ${ }^{8}$ The study by Savoldi et $\mathrm{al}^{7}$ showed that the risk of eradication failure of clarithromycin-resistant strains of $H$. pylori was seven times higher than that of the sensitive strains (odds ratio $(\mathrm{OR})=$ 6.97; 95\% confidence interval (CI): 5.23-9.28; $\mathrm{P}<0.001)$, eight times higher for levofloxacin-resistant strains $(\mathrm{OR}=$ 8.18; 95\% CI: 3.81-17.56; $\mathrm{P}<0.001)$, and 2.5 times higher for metronidazole-resistant strains $(\mathrm{OR}=2.52$; 95\% CI: 1.82-3.48; $\mathrm{P}<0.001)$. The risk of failure of H. pylori eradication is significantly related to antibiotic resistance. Although the empirical treatment scheme is simple and practicable, it inevitably causes some drugresistant patients to adopt unsuitable eradication scheme, leading to the failure of eradication, which aggravates the antibiotic resistance. Individualized treatment is the main direction in the future, as it can significantly improve the eradication rate, reduce the abuse of antibiotics, and avoid secondary antibiotic resistance. ${ }^{3-6}$

Bacterial culture and antibiotic drug sensitivity tests are the gold standards for the phenotypic sensitivity test of H. pylori, which provide reliable information for the development of individualized clinical programs ${ }^{9}$. However, although this method has already been mature, because of the long time required and high requirements for laboratory environment, most clinical laboratories, especially small and medium-sized hospitals in China, are not willing to carry out this clinical project on a large scale, and most patients are not willing to wait for two weeks to be treated. Therefore, more rapid and convenient molecular detection technology is ready.

The detection of antibiotic sensitive genotypes of H. pylori could be applied for the accurate and economical diagnosis and treatment of many diseases. The current study shows that clarithromycin and levofloxacin gene resistance is consistent with the phenotypic resistance of $H$. pylori. ${ }^{10,11}$ However, in view of the correlation between drug-resistant gene mutation and clinical treatment effect have not yet been fully elucidated, especially in China, and hence, we tried to further verify their consistency and the improvement of eradication rate by antibiotic sensitivity gene test guided eradication therapy. This could be effectuated by detecting the mutation in the drug resistance site, testing the sensitivity of antibiotics in vitro, following up the efficacy of clinical eradication therapy, and analyzing the general data (demography, clinical diagnosis, and histopathology diagnosis) of the patients with primary $H$. pylori infection.

\section{Materials and Methods Study Population}

This prospective, single-center study consisted of adult patients with dyspepsia, recruited from October 2017 to October in 2018, and were referred for upper endoscopy at Peking University Third Hospital with confirmed $H$. pylori infection. The exclusion criteria were as follows: previously underwent eradication treatment for $H$. pylori infection; age < 18 years; administered drugs, such as proton pump inhibitor, $\mathrm{H}_{2}$ receptor blockers, bismuth, and antibiotics in the last 4 weeks; malignant gastrointestinal tumor; underwent previous gastric or esophageal surgery; Zollinger-Ellison syndrome; pregnant women, lactating women, or alcoholics.

\section{Study Design}

The subjects were selected based on their eligibility according to the inclusion and exclusion criteria. After enrollment, the demographic data were collected. During upper endoscopy examination, a piece of the mucosal biopsy was taken at the lesser curvature of the antrum for rapid urease test (RUT; HPUT-H102, San Qiang Bio \& Chem, Fujian, China). If RUT was positive, gastric biopsies were performed: two from the antrum and two from the corpus. Of these, two (one each of antrum and corpus, respectively) were used for histological examination and the remaining for $H$. pylori culture and drug sensitivity tests (including amoxicillin, clarithromycin, metronidazole, levofloxacin, and tetracycline) to determine the phenotypic resistance of $H$. pylori strains. Then, the strains were subjected to genome-wide sequencing by High-Throughput Nucleotide Sequencing technology to analyze genetic determinants of $H$. pylori antibiotic resistance to clarithromycin and levofloxacin.

Subjects with successful both $H$. pylori culture and sequencing received clinical eradication therapy with a triple plus bismuth regimen (esomeprazole $20 \mathrm{mg}$, amoxicillin $1000 \mathrm{mg}$, clarithromycin $500 \mathrm{mg}$, and bismuth potassium citrate $220 \mathrm{mg}$, twice daily for 14 days), and the eradication efficacy was evaluated 8 weeks after the eradication treatment. 


\section{Methods}

Histological Assessment

Biopsy specimens of gastric mucosa were fixed in formalin and embedded in paraffin. The paraffin sections were stained with hematoxylin and eosin staining for histopathological evaluation and Warthin-Starry staining for H. pylori detection. Histological sections of the antrum and corpus tissue were graded for $H$. pylori density, the intensity of acute inflammatory cell infiltration, the intensity of chronic inflammatory cell infiltration, chronic atrophic gastritis, and intestinal metaplasia according to the Classification and Grading of Gastritis in the Updated Sydney System. ${ }^{12}$

\section{H. pylori Strain Culture and Antimicrobial Susceptibility Testing}

H. pylori strains were isolated and cultured from the gastric mucosal samples. In vitro, antibiotic resistance was evaluated by the Epsilometer test (E-Test, AB Biodisk, Sweden). H. pylori strains with minimal inhibitory concentrations $(\mu \mathrm{g} / \mathrm{mL})$ of $>0.125,>0.5,>8,>1$, and $>1$ showed resistance to amoxicillin, clarithromycin, metronidazole, levofloxacin, and tetracycline according to the guidelines of the European Committee on Antimicrobial Susceptibility Testing breakpoints (EUCAST, available in http://www.eucast.org/), respectively.

\section{Genotype Analysis of Antibiotic Susceptibility}

Genetic determinants of $H$. pylori antibiotic resistance to clarithromycin and levofloxacin were analyzed by highthroughput nucleotide sequencing technology. The total genomic DNA of $H$. pylori isolates was extracted using the Universal Genomic DNA Kit (Cwbiotech, Jiangsu, China). The extracted DNA was processed by DNA fragment enzyme, the DNA library was prepared by the rapid preparation kit, and sequenced on the Beijing Genomics Institute platform (MGISEQ-2000, MGI Tech Co. Ltd, Beijing, China). Trim Galore was used for quality control of the DNA sequence that was then compared to the reference genome by BWA; Picard was used for preprocessing, and finally, the mutation site was identified by bcftools. It was peptidyl transferase in the $\mathrm{V}$ domain of $23 \mathrm{~S}$ rRNA related to clarithromycin resistance, and gyrA was related to levofloxacin resistance; all the genetic variations of $23 S$ rRNA and gyrA were analyzed and compared to $H$. pylori 26,695. These variants were summarized and analyzed statistically with respect to the resistance phenotype using Fisher's exact test.

\section{Treatment Regimens}

Triple plus bismuth therapy: esomeprazole $20 \mathrm{mg}$ twice daily, amoxicillin $1000 \mathrm{mg}$ twice daily, clarithromycin $500 \mathrm{mg}$ twice daily, and bismuth potassium citrate $220 \mathrm{mg}$ twice daily for 14 days. A ${ }^{13} \mathrm{C}$-UBT (urea breath test, UBT; UCBT Kit, Atom High Tech, Beijing, China) was used to confirm the presence of $H$. pylori infection after about 8 weeks of eradication, and $H$. pylori infection was considered eradicated if the ${ }^{13} \mathrm{C}$-UBT test was negative.

\section{Statistical Analysis}

The sample size was calculated by Pass software. Statistical analysis was performed using SPSS for Windows (version 18; IBM Inc., NY, USA). Two-sided $\mathrm{P}<0.05$ indicated statistical significance. Categorical variables were described as percentages or frequencies, while continuous variables were described as means \pm standard deviation. The eradication rates and $95 \%$ CIs were calculated. Intergroup differences were evaluated using Pearson's chi-square or Fisher's exact test for categorical variables and Student's $t$-test for continuous variables. A multiple logistic regression analysis was performed using all variables with statistical significance in multivariate analysis. The accuracy of antibiotic sensitivity gene test in diagnosing $H$. pylori strain susceptibility and its consistency with gold-standard (drug sensitivity tests) was evaluated by receiver operating characteristic (ROC) curve and consistency of the diagnostic test.

\section{Results \\ Characteristics of the Participants}

The study flowchart was presented in Figure 1. A total of 551 subjects were included, with an average age of $40.0 \pm$ 12.2 years old, and the ratio of male to female was about 1:1.1. The endoscopic findings and histopathological diagnosis were as follows: $70(12.7 \%)$ cases of peptic ulcer and $481(87.3 \%)$ cases of non-ulcer dyspepsia were diagnosed by endoscopist. Ninety $(16.3 \%)$ cases of chronic atrophic gastritis, $461(83.7 \%)$ cases of chronic nonchronic atrophic gastritis, $130(23.6 \%)$ cases of intestinal metaplasia, $312(56.6 \%)$ cases of lymphocyte aggregation and $24(4.4 \%)$ cases of dysplasia were diagnosed by pathologist. 


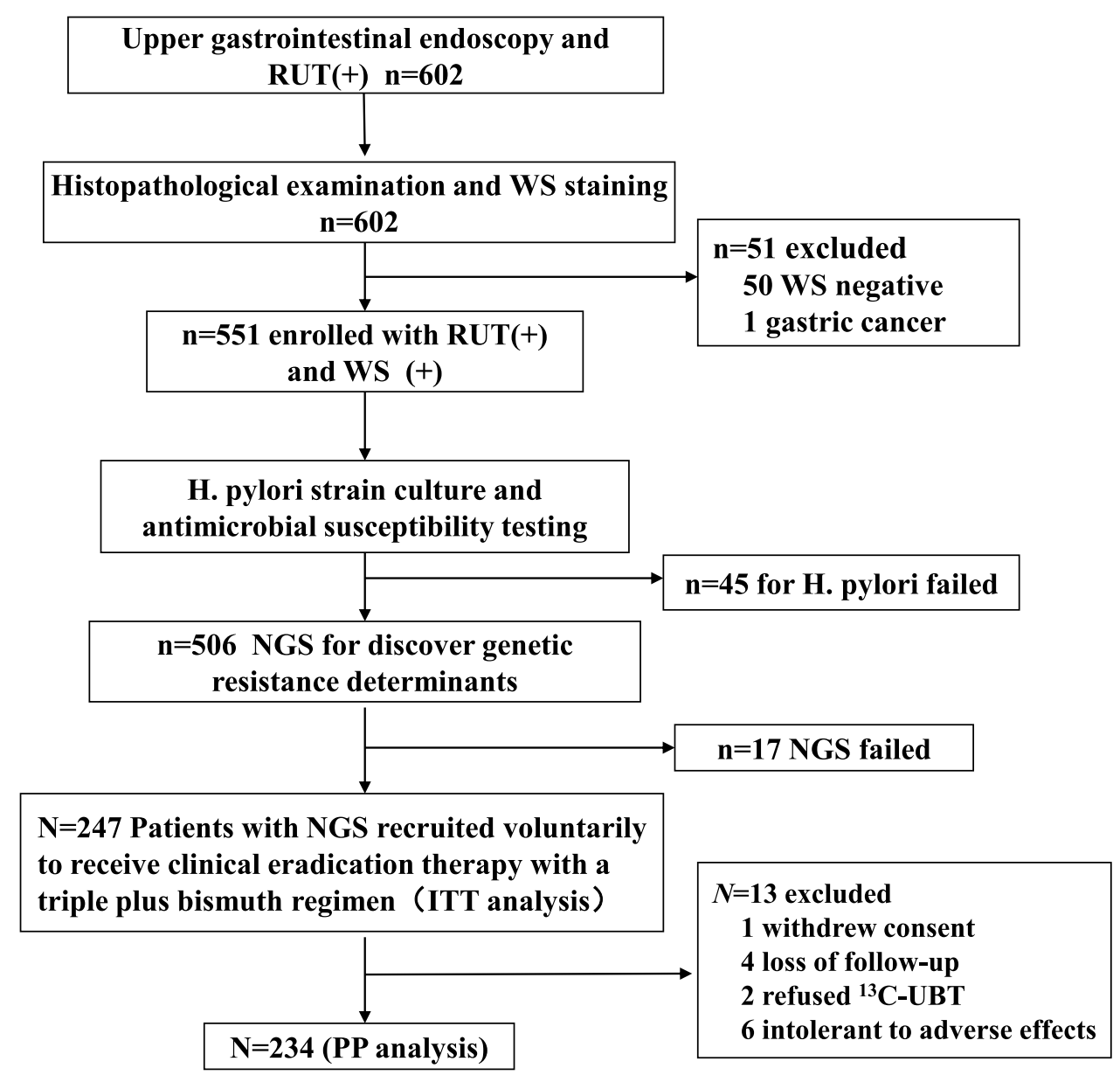

Figure I Flow chart of the study.

Abbreviations: RUT, rapid urease test; WS, Warthin-Starry staining; NGS, next-generation sequencing; UBT, ${ }^{13}$ C-urea breath test; ITT, intention-to-treat; PP, per-protocol.

\section{Phenotypic Analysis of Antibiotic Susceptibility}

A total of 551 samples of gastric mucosa biopsy were cultured for H. pylori and E-test, of which 506 (91.8\%) were cultured successfully. The results showed that the resistance rates of $H$. pylori to five antibiotics were as follows: amoxicillin $2.6 \% \quad(13 / 506)$, clarithromycin $38.9 \%$ (196/506), metronidazole 57.3\% (290/506), levofloxacin $31.0 \%(157 / 506)$, and tetracycline $6.3 \%(32 / 506)$.

\section{Genotype Analysis of Antibiotic Susceptibility}

489/506 (96.6\%) H. pylori strains were subjected to highthroughput nucleotide sequencing to obtain sequencing data. Among 489 H. pylori isolates, 189 mutations in clarithromycin resistant were detected, with a genotypic resistant rate of $38.7 \%$. The most common mutant sites of clarithromycin resistant genes were A2143G (188/189,
99.5\%) and $\mathrm{A} 2142 \mathrm{G}(3 / 189,1.6 \%)$. One hundred and twenty-nine mutations conditioning resistance to levofloxacin were detected with a genotypic resistant rate of $26.4 \%$. Most of the mutations were found in N87K (71/ $129,55.0 \%)$, followed by D91N $(28 / 129,21.7 \%)$, D91G $(20 / 129,15.5 \%)$, D91Y $(8 / 129,6.2 \%)$, and N87I (8/ $129,6.2 \%)$.

A total of $66 \mathrm{H}$. pylori isolates had both levofloxacin and clarithromycin mutations and the double resistance rate was $13.5 \%(66 / 489)$.

\section{Eradication Rate of $H$. pylori Infection with Triple Plus Bismuth Therapy}

A total of 247 subjects who voluntarily received triple plus bismuth eradication therapy were included in ITT analysis. After 13 subjects were excluded, 234 subjects completed the eradication treatment, which included PP analysis, and 179 subjects succeeded in eradication therapy. The eradication rate $H$. pylori was $72.5 \%$ (95\% CI: $66.9-78.1 \%$ ) in 
ITT analysis and $76.5 \%(95 \%$ CI: $71.0-82.0 \%)$ in PP analysis.

\section{Analysis of the Related Factors of Gene Resistance}

Among the 489 subjects, 192 (39.3\%) H. pylori strains were determined as clarithromycin resistant by phenotypic drug sensitivity tests, and 189 (38.7\%) displayed point mutations in domain $\mathrm{V}$ of $23 \mathrm{~S}$ rRNA gene. The 155 (31.7\%) H. pylori strains were determined to be resistant to levofloxacin by phenotypic drug sensitivity tests, and 129 (26.4\%) displayed point mutations in the gyrA gene. The difference in the resistance rate of clarithromycin and levofloxacin between the genotype and phenotype was not statistically significant $(\mathrm{P}=0.896$ and $\mathrm{P}=0.078$, respectively).

Based on the phenotypic resistance as the gold standard, the value of resistant gene mutation in the diagnosis of antibiotic resistance was evaluated: the AUC for the diagnosis with resistance gene mutation of $H$. pylori strains was 0.877 for clarithromycin $(95 \%$ CI: 0.840 $0.913, \mathrm{P}<0.001)$ and 0.838 for levofloxacin $(95 \% \mathrm{CI}$ : 0.794-0.883, $\mathrm{P}<0.001$ ), respectively.

According to the ROC curve, the cutoff value of the mutation frequency of clarithromycin and levofloxacin resistance gene of $H$. pylori was $20 \%$. The sensitivity and specificity of resistance gene mutations in the diagnosis of $H$. pylori resistance are shown in Table 1. The kappa values were $0.703(\mathrm{P}<0.001)$ for clarithromycin and $0.664(\mathrm{P}<0.001)$ for levofloxacin. Irrespective of clarithromycin or levofloxacin, the genetic resistance and phenotypic resistance were highly consistent.

\section{Correlation Analysis Between Gene Resistance and Clinical Therapeutic Effect}

The eradication rate of $H$. pylori in the clarithromycin gene-resistant group was significantly lower than that in the gene-susceptible group $(\mathrm{P}<0.001$; Table 2$)$. The correlation analysis revealed that the genotypic resistance rate of clarithromycin decreased with increasing age, and a negative correlation was established between genotypic resistance and age in clarithromycin ( $\mathrm{P}=0.036)$; the genotypic resistance rate of levofloxacin increased with increasing age and a positive correlation was established between genotypic resistance and age in levofloxacin $(\mathrm{P}=0.040)$. In addition, the genotypic resistance rate of levofloxacin in chronic atrophic gastritis was significantly

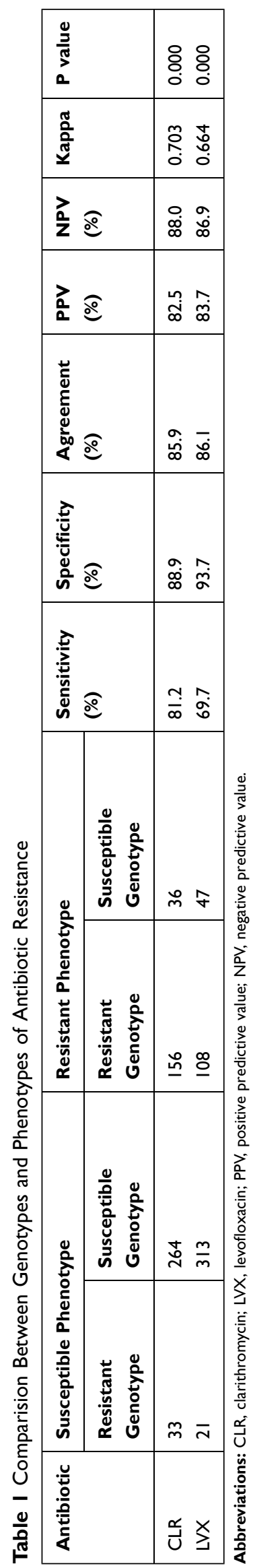


Table 2 The Relationship Between Genotype Resistance of Clarithromycin and Eradication Efficacy

\begin{tabular}{|c|c|c|c|c|c|c|c|}
\hline & \multirow[t]{2}{*}{ Total } & \multicolumn{2}{|c|}{ Resistant Genotype } & \multicolumn{2}{|c|}{ Susceptible Genotype } & \multirow[t]{2}{*}{$\chi^{2}$} & \multirow[t]{2}{*}{ P-value } \\
\hline & & $\mathbf{n}$ & $\begin{array}{l}\text { Eradication Rate } \\
\text { n }(\%, 95 \% \mathrm{Cl})\end{array}$ & $\mathbf{n}$ & $\begin{array}{l}\text { Eradication Rate } \\
\text { n }(\%, 95 \% \mathrm{Cl})\end{array}$ & & \\
\hline PP-analysis & 234 & 86 & $49(57.0,46.3-67.7)$ & 148 & $130(87.8,82.5-93.2)$ & 28.813 & $<0.001$ \\
\hline ITT-analysis & 247 & 94 & $49(52.1,41.8-62.4)$ & 153 & $130(85.0,79.2-90.7)$ & 31.474 & $<0.001$ \\
\hline
\end{tabular}

Table 3 The Relationship Between the Baseline at Enrollment and the Antibiotic Resistance of Pylori Isolates by NGS

\begin{tabular}{|c|c|c|c|c|c|c|c|}
\hline \multirow[t]{2}{*}{ Factors } & \multirow[t]{2}{*}{$\mathbf{N}$} & \multicolumn{3}{|c|}{ Resistant Genotype of Clarithromycin } & \multicolumn{3}{|c|}{ Resistant Genotype of Levofloxacin } \\
\hline & & $\begin{array}{l}\text { Mutation } \\
\text { Rate (\%) }\end{array}$ & $\begin{array}{l}\text { Univariate } \\
\text { Analysis } \\
\text { P value }\end{array}$ & $\begin{array}{l}\text { Multivariate } \\
\text { Analysis } \\
\text { P value }\end{array}$ & $\begin{array}{l}\text { Mutation } \\
\text { Rate (\%) }\end{array}$ & $\begin{array}{l}\text { Univariate } \\
\text { Analysis } \\
\text { P value }\end{array}$ & $\begin{array}{l}\text { Multivariate } \\
\text { Analysis } \\
\text { P value }\end{array}$ \\
\hline $\begin{array}{l}\text { Gender } \\
\text { Female } \\
\text { Male }\end{array}$ & $\begin{array}{l}256 \\
233\end{array}$ & $\begin{array}{l}41.0 \\
36.1\end{array}$ & 0.260 & 0.400 & $\begin{array}{l}28.1 \\
24.5\end{array}$ & 0.359 & 0.334 \\
\hline $\begin{array}{l}\text { Age } \\
\qquad 35 \text { YO } \\
\quad 35-50 Y O \\
>50 Y O\end{array}$ & $\begin{array}{l}187 \\
195 \\
107\end{array}$ & $\begin{array}{l}44.4 \\
36.9 \\
31.8\end{array}$ & 0.083 & 0.036 & $\begin{array}{l}18.7 \\
30.3 \\
32.7\end{array}$ & 0.009 & 0.040 \\
\hline $\begin{array}{l}\text { Clinical diagnosis } \\
\text { PUD } \\
\text { NUD }\end{array}$ & $\begin{array}{l}63 \\
426\end{array}$ & $\begin{array}{l}30.2 \\
39.9\end{array}$ & 0.138 & 0.220 & $\begin{array}{l}25.4 \\
36.5\end{array}$ & 0.849 & 0.868 \\
\hline $\begin{array}{l}\text { Chronic atrophic gastritis } \\
\text { CAG } \\
\text { Non-CAG }\end{array}$ & $\begin{array}{l}81 \\
408\end{array}$ & $\begin{array}{l}44.4 \\
37.5\end{array}$ & $0.24 I$ & 0.341 & $\begin{array}{l}40.7 \\
23.5\end{array}$ & 0.001 & 0.044 \\
\hline $\begin{array}{l}\text { Intestinal metaplasia } \\
\text { IM } \\
\text { Non-IM }\end{array}$ & $\begin{array}{l}117 \\
372\end{array}$ & $\begin{array}{l}41.9 \\
37.6\end{array}$ & 0.411 & 0.666 & $\begin{array}{l}34.2 \\
23.9\end{array}$ & 0.028 & 0.879 \\
\hline $\begin{array}{l}\text { Lymphoid aggregates } \\
\text { Yes } \\
\text { No }\end{array}$ & $\begin{array}{l}266 \\
223\end{array}$ & $\begin{array}{l}40.6 \\
36.3\end{array}$ & 0.333 & 0.304 & $\begin{array}{l}20.7 \\
33.2\end{array}$ & 0.430 & 0.590 \\
\hline
\end{tabular}

Abbreviations: PUD, peptic ulcer disease; NUD, non-ulcerative dyspepsia; CAG, chronic atrophic gastritis; IM, intestinal metaplasia.

higher than that in non-chronic atrophic gastritis $(\mathrm{P}=0.044$; Table 3).

\section{Discussion}

With the increasing rate of antibiotic resistance, especially clarithromycin, levofloxacin, and metronidazole, the efficacy of empirical eradication therapy for $H$. pylori infection showed a significant downward trend in most countries and regions. Individualized treatment mode is an important direction of exploration with respect to the treatment of $H$. pylori infection in the future. Also, because of its strict requirements for laboratory environment and long culture period, drug sensitivity test was limited in clinical application. Methods evaluating the detection of mutations related to antibiotic resistance of H. pylori would promote rapid, accurate, cost-effective individual diagnosis and treatment.

The mechanism of drug resistance in $H$. pylori is mainly related to the point mutations located on the chromosome., Resistance to clarithromycin in $H$. pylori is caused by several point mutations in the $r r l$ gene encoding two $23 \mathrm{~S}$ rRNA nucleotides: A2142C, A2142G, A2143G, A2143C, T2182C, etc. and the first three are the most frequent mutations. ${ }^{13-16}$ The fluoroquinolone resistance of $H$. pylori depends on the 
point mutations in the quinolone resistance-determining region of the gyrA gene at the positions encoding these amino acids, and the most frequent mutations are found at codons 87 and 91 of the gyrA gene. ${ }^{17}$ There are regional differences in $H$. pylori resistance-related mutation sites ${ }^{18-20}$ and the regional differences should be focused upon to avoid false negatives. Our study confirmed the resistant mutation sites of $H$. pylori to clarithromycin and levofloxacin in Beijing and provided reliable data for further development of the relevant mutation sites with respect to resistance genes.

Since it is clear that $H$. pylori resistance is mainly related to point mutation of related genes, the consistency of drug resistance gene mutation with bacterial phenotype resistance and clinical efficacy is the key to individualized clinical treatment. The majority of the studies show that the presence of mutations in genes encoding targets of clarithromycin and levofloxacin were consistent with the results of drug sensitivity tests and clinical efficacy of H. pylori. ${ }^{10,11,21,22}$ An high-throughput nucleotide sequencing study of $55 \mathrm{H}$. pylori strains in Cambodia ${ }^{10}$ demonstrated that the mutations resistance genes of clarithromycin, levofloxacin and amoxicillin were at $23 \mathrm{~S}$ rRNA, gyrA, and $p b p l$ and these sites were consistent with the phenotypic resistance; however, the gene mutations of metronidazole and tetracycline were not consistent with the phenotypic resistance. In our study, the coincidence rate of genotypic and phenotypic resistance was $85.9 \%$ for clarithromycin and $86.1 \%$ for levofloxacin, and the genotypic analysis of antibiotic susceptibility could be used in clinical medication guidance.

Furthermore, we explored the correlation between the genotype of antibiotic susceptibility and clinical treatment. The total eradication rate was $76.5 \%$ (PP analysis) in the triple bismuth plus treatment. In the case of clarithromycin genotypic resistance, the eradication rate in the generesistant group (57\%) was significantly lower than that in the gene-sensitive group $(87.8 \%)$, while the eradication rate of the clarithromycin-sensitive group was $>30 \%$ higher than in the antibiotic-resistant group (ITT analysis), suggesting that individualized treatment guided by the genotype of antibiotic susceptibility can effectively improve the eradication rate. In a cohort study in Chile, ${ }^{16}$ clarithromycin resistance was negatively correlated with the eradication rate $(\mathrm{OR}=0.13 ; 95 \%$ CI $0.04-0.49)$, ie, the eradication rate of patients being infected by clarithromycin-resistant $H$. pylori strains decreased significantly. The study by Gao et $\mathrm{al}^{23}$ showed that according to the results of $H$. pylori resistance gene detection (amoxicillin PBP1, clarithromycin $23 S$ rRNA, levofloxacin gyrA, tetracycline $16 S$ rRNA), 111 cases underwent initial treatment and 150 cases were treated again. The eradication rate in two groups was $>90 \%$, and no serious adverse event occurred. Thus, the present study speculated that the clinical treatment guided by the genotype of antibiotic susceptibility can achieve satisfactory clinical efficacy and safety.

Although it is not recommended in some consensus and guidelines that the patients with clarithromycinresistant $H$. pylori use standard triple regimens containing clarithromycin, ${ }^{3-6}$ some studies ${ }^{24-26}$ showed that although the drug resistance rate of clarithromycin has increased significantly, bismuth can overcome the drug resistance and achieve a satisfactory eradication effect. Probably due to interfering with iron metabolism of $H$. pylori and the synergistic effect of bismuth, the addition of this drug to a triple therapy with clarithromycin may allow achieving a cure rate of approximately $90 \%$ even in patients with resistance against this antibiotic. ${ }^{27}$ In addition, considering that this eradicated regimen is the most commonly used in China and since no study has explored the correlation between gene resistance and the therapeutic effect, we explored the triple bismuth plus program under the premise of complying with the agreement of the patients. A meta-analysis ${ }^{28}$ showed that for clarithromycinsensitive strains, the eradication rate of clarithromycin triple therapy was $88.8 \%$, while the eradication rate of clarithromycin-resistant strains was only $36.3 \%$. The eradication rate of clarithromycin-resistant strains was $57 \%$, which was $20 \%$ higher than the standard triple in the literature.

Furthermore, we analyzed the presence of putative factors of gene resistance by analyzing the demographic characteristics and gastric mucosa-related histology. These results showed that the resistance rate to levofloxacin of $H$. pylori strains isolated from patients with atrophic gastritis was significantly higher than that of non-atrophic gastritis. The relationship between gastric mucosa histology and $H$. pylori resistance remains controversial. ${ }^{29}$ However, we speculated that any change in the complex microenvironment in the stomach and the corresponding immune response of the body against $H$. pylori infection might lead to a series of cascade reactions of $H$. pylori. Bayati et $\mathrm{al}^{30}$ demonstrated that the resistance rates of intestinal metaplasia patients to clarithromycin, metronidazole, and ciprofloxacin were significantly higher than those of chronic gastritis and severe active gastritis. In 
the current study, the genetic resistance rate of clarithromycin showed a negative correlation with age $(\mathrm{P}=0.036)$, while that of levofloxacin showed a positive correlation with age $(\mathrm{P}=0.040)$. This phenomenon could be ascribed to the wide use of quinolones in the respiratory tract infection in the elderly, while fluoroquinolones are contraindicated in children, and clarithromycin is commonly used in children with respiratory tract infection. ${ }^{7}$ In another study from China, ${ }^{31}$ the drug resistance rate of clarithromycin in children aged $13-18$ years $(14.31 \%)$ was significantly lower than that in children aged $7-12$ years $(21.75 \%)$ and $0-6$ years $(19.35 \%)$. With the advancing age of the children, clarithromycin resistance decreased $(\mathrm{P}=0.002)$. A meta-analysis ${ }^{7}$ of 66,142 strains isolated from 178 studies across 65 countries showed that the resistance rate of levofloxacin in adults in most regions was higher than that in children, while the resistance rate of clarithromycin in children in the Western Pacific (85\%) was significantly higher than that in adults $(32 \%)$; these findings were consistent with the current results.

The current study has several limitations. Firstly, this is a single-center study, and hence, the results might not be sufficient to reflect the $H$. pylori resistance patterns in the general population. Secondly, this is not an intervention study, and further randomized clinical trial study on gene resistance tests are required in the future to clarify the effect of individualized diagnosis and treatment based on H. pylori gene detection. In addition, the present study only evaluates the correlation between clarithromycin resistance of $H$. pylori and clinical eradication effect. Owing to the consistency between the gene resistance and phenotype resistance of levofloxacin, it is speculated that the detection of genetic resistance of levofloxacin can also be used in individualized diagnosis and treatment in the future to aid the drug selection for customized clinical treatment. The more expensive high-throughput nucleotide sequencing method was used in this study, and the major clarithromycin and levofloxacin drug-resistant gene mutation sites of $H$. pylori were found and tested. This study provides a theoretical basis for the further use of a more economical and simple PCR method and even the drug resistance gene detection kit, so as to make the detection of H. pylori resistance more widely used in clinical practice.

\section{Conclusions}

In summary, H. pylori gene-resistance of clarithromycin and levofloxacin were further verified by high-throughput nucleotide sequencing technology, and which were consistent with antimicrobial susceptibility testing in our study.
Meanwhile, the relationship between clarithromycin generesistance and the effect of eradication therapy was analyzed retrospectively. Therefore, our study laid an experimental foundation and clinical application for the detection of Helicobacter pylori resistance gene.

\section{Ethics Approval and Informed Consent}

The study protocol was approved by the Medical Ethics Committee of Peking University Third Hospital (Approval Number: 2017-262-01) complied with the Declaration of Helsinki. All participants voluntarily provided informed consent before participation in this study and all the data were analyzed anonymously.

\section{Acknowledgments}

We thank the Clinical Epidemiology Research Center of Peking University Third Hospital for help with the statistical treatment of the data. We also thank the members of the Department of Gastroenterology, Peking University Third Hospital for their support.

\section{Author Contributions}

All authors made substantial contributions to the work, including conception and study design, acquisition of data, analysis and interpretation of data and etc.; all authors also took part in drafting, revising or critically reviewing the article; gave final approval of the version to be published; had agreed on the journal to which the article had been submitted; and agreed to be accountable for all aspects of the work.

\section{Funding}

This study was supported by the Key Laboratory for Helicobacter pylori Infection and Upper gastrointestinal Diseases in Beijing, China (No.BZ0371).

\section{Disclosure}

All authors declare no conflicts of interest related to this article.

\section{References}

1. Hooi JKY, Lai WY, Ng WK, et al. Global Prevalence of Helicobacter pylori Infection: systematic Review and Meta-Analysis. Gastroenterology. 2017;153(2):420-429. doi:10.1053/j.gastro.2017.04. 022

2. Zhou LY, Lin SR, Ding SG, et al. Relationship of Helicobacter pylori eradication with gastric cancer and gastric mucosal histological changes: a 10-year follow-up study. Chin Med J. 2014;127 (8):1454-1458. 
3. Chey WD, Leontiadis GI, Howden CW, Moss SF. ACG Clinical Guideline: treatment of Helicobacter pylori Infection. Am J Gastroenterol. 2017;112:212-238. doi:10.1038/ajg.2016.563

4. Malfertheiner P, Megraud F, O'Morain CA, et al. Management of Helicobacter pylori infection-the Maastricht V/Florence Consensus Report. Gut. 2017;66:6-30. doi:10.1136/gutjnl-2016-312288.

5. Fallone CA, Chiba N, van Zanten SV, et al. The Toronto Consensus for the Treatment of Helicobacter pylori Infection in Adults. Gastroenterology. 2016;151(1):51-69.e14. doi:10.1053/j.gastro.2016.04.006

6. Liu WZ, Xie Y, Lu H, et al. Chinese Society of Gastroenterology, Chinese Study Group on Helicobacter pylori and Peptic Ulcer. Fifth Chinese National Consensus Report on the management of Helicobacter pylori infection. Helicobacter. 2018;23(2):e12475. doi: $10.1111 /$ hel.12475

7. Savoldi A, Carrara E, Graham DY, Conti M, Tacconelli E. Prevalence of Antibiotic Resistance in Helicobacter pylori: a Systematic Review and Meta-analysis in World Health Organization Regions. Gastroenterology. 2018;155(5):1372-1382.e17. doi:10.1053/j.gastro.2018.07.007

8. Tacconelli E, Carrara E, Savoldi A, et al. Discovery, research, and development of new antibiotics: the WHO priority list of antibiotic-resistant bacteria and tuberculosis. Lancet Infect Dis. 2018;18(3):318-327. doi:10.1016/S1473-3099(17)30753-3

9. Gerrits MM, van Vliet AH, Kuipers EJ, Kusters JG. Helicobacter pylori and antimicrobial resistance: molecular mechanisms and clinical implication. Lancet Infect Dis. 2006;6(11):699-709. doi:10.1016/ S1473-3099(06)70627-2

10. Tuan VP, Narith D, Tshibangu-Kabamba E, et al. A Next-Generation Sequencing-Based Approach to Identify Genetic Determinants of Antibiotic Resistance in Cambodian Helicobacter pylori Clinical Isolates. J Clin Med. 2019;8:858. doi:10.3390/jcm8060858

11. Lauener FN, Imkamp F, Lehours P, et al. Genetic Determinants and Prediction of Antibiotic Resistance Phenotypes in Helicobacter pylori. J Clin Med. 2019;8(1):53. doi:10.3390/jcm8010053.

12. Dixon MF, Genta RM, Yardley JH, Correa P. Classification and Grading of Gastritis. The Updated Sydney System. International Workshop on the Histopathology of Gastritis. Houston. 1996;20(10):1161-1181. doi:10.1097/00000478-199610000-00001

13. Wang YH, Wang FF, Gong XL, et al. Genotype profiles of Helicobacter pylori from gastric biopsies and strains with antimicrobial-induced resistance. Therap Adv Gastroenterol. 2020;13:1756284820952596. doi:10.1177/1756284820952596.

14. Seo SI, Do BJ, Kang JG, et al. Helicobacter pylori Eradication According to Sequencing-Based 23S Ribosomal RNA Point Mutation Associated with Clarithromycin Resistance. J Clin Med. 2019;9(1):54. doi:10.3390/jcm9010054

15. Van den Poel B, Gils S, Micalessi I. et al. Molecular detection of Helicobacter pylori and clarithromycin resistance in gastric biopsies: a prospective evaluation of RIDA ${ }^{\circledR}$ GENE Helicobacter pylori assay. Acta Clin Belg;2019. 1-7. doi:10.1080/17843286.2019.1685741

16. Arenas A, Serrano C, Quiñones L, et al. High prevalence of clarithromycin resistance and effect on Helicobacter pylori eradication in a population from Santiago, Chile: cohort study and meta-analysis. Sci Rep. 2019;9(1):20070. doi:10.1038/s41598-019-56399-7

17. Arslan N, Yılmaz O, Demiray-Gürbüz E. Importance of antimicrobial susceptibility testing for the management of eradication in Helicobacter pylori infection. World J Gastroenterol. 2017;23 (16):2854-2869. doi:10.3748/wjg.v23.i16.2854
18. van Doorn LJ, Glupczynski Y, Kusters JG, et al. Accurate prediction of macrolide resistance in Helicobacter pylori by a PCR line probe assay for detection of mutations in the 23S rRNA gene: multicenter validation study. Antimicrob Agents Chemother. 2001;45 (5):1500-1504. doi:10.1128/AAC.45.5.1500-1504.2001

19. Shetty V, Lamichhane B, Tay CY, et al. High primary resistance to metronidazole and levofloxacin, and a moderate resistance to clarithromycin in Helicobacter pylori isolated from Karnataka patients. Gut Pathog. 2019;11(1):21. doi:10.1186/s13099-019-0305-x

20. Salehi N, Attaran B, Eskini N, et al. New insights into resistance of Helicobacter pylori against third- and fourth-generation fluoroquinolones: a molecular docking study of prevalent GyrA mutations. Helicobacter. 2019;24(5):e12628. doi:10.1111/hel.12628

21. Kageyama C, Sato M, Sakae H, et al. Increase in antibiotic resistant Helicobacter pylori in a University Hospital in Japan. Infect Drug Resist. 2019;12:597-602. doi:10.2147/IDR.S196452

22. Zhang XY, Shen WX, Chen CF, et al. Detection of the clarithromycin resistance of Helicobacter pylori in gastric mucosa by the amplification refractory mutation system combined with quantitative real-time PCR. Cancer Med. 2019;8(4):1633-1640. doi:10.1002/cam4.1986

23. Gao C, Du SY, Fang L, Fan YH, Song AP, Chen H. Eradication Treatment of Helicobacter pylori Infection Based on Molecular Pathologic Antibiotic Resistance. Infect Drug Resist. 2020;13:69-79. doi:10.2147/IDR.S232169

24. Graham DY, Dore MP, Lu H. Understanding treatment guidelines with bismuth and non-bismuth quadruple Helicobacter pylori eradication therapies. Expert Rev Anti Infect Ther. 2018;16(9):679-687. doi:10.1080/14787210.2018.1511427

25. Zhang W, Chen Q, Liang X, et al. Bismuth, lansoprazole, amoxicillin and metronidazole or clarithromycin as first-line Helicobacter pylori therapy. Gut. 2015;64(11):1715-1720. doi:10.1136/gutjnl-2015-309900

26. McNicholl AG, Bordin DS, Lucendo A, et al. Combination of bismuth and standard triple therapy eradicates helicobacter pylori infection in more than $90 \%$ of patients. Clin Gastroenterol Hepatol. 2020;18(1):89-98. doi:10.1016/j.cgh.2019.03.048

27. Gisbert JP, McNicholl AG. Optimization strategies aimed to increase the efficacy of $\mathrm{H}$. pylori eradication therapies. Helicobacter. 2017;22 (4):e12392. doi:10.1111/hel.12392

28. Chen MJ, Chen CC, Chen YN, et al. Systematic Review with Meta-Analysis: concomitant Therapy vs. Triple Therapy for the First-Line Treatment of Helicobacter pylori Infection[J]. Am $J$ Gastroenterol. 2018;113(10):1444-1457. doi:10.1038/s41395-0180217-2

29. Boyanova L, Ilieva J, Gergova G, et al. Numerous risk factors for Helicobacter pylori antibiotic resistance revealed by extended anamnesis: a Bulgarian study. J Med Microbiol. 2012;61:85-93. doi:10.1099/jmm.0.035568-0

30. Bayati S, Alebouyeh M, Amirmozafari N, Ebrahimi Daryani N, Talebi M, Zali MR. Histological changes in refractory Helicobacter pylori infection and its relationship with increased levels of resistance to antibiotics and therapeutic regimens: one-year follow-up. APMIS. 2020;128(1):25-34. doi:10.1111/apm.13001

31. Li L, Ke Y, Yu C, et al. Antibiotic resistance of Helicobacter pylori in Chinese children: a multicenter retrospective study over 7 years. Helicobacter. 2017;22(3):e12373. doi:10.1111/hel.12373 


\section{Publish your work in this journal}

Infection and Drug Resistance is an international, peer-reviewed openaccess journal that focuses on the optimal treatment of infection (bacterial, fungal and viral) and the development and institution of preventive strategies to minimize the development and spread of resistance. The journal is specifically concerned with the epidemiology of antibiotic resistance and the mechanisms of resistance development and diffusion in both hospitals and the community. The manuscript management system is completely online and includes a very quick and fair peerreview system, which is all easy to use. Visit http://www.dovepress.com/ testimonials.php to read real quotes from published authors. 